\title{
Switching on the notochord
}

\author{
Vincent T. Cunliffe and Philip W. Ingham ${ }^{1}$ \\ Developmental Genetics Programme, University of Sheffield, Sheffield S10 2TN, UK
}

The notochord is a defining characteristic of the chordate embryo. It is a dorsally located rod of tensile mesodermal tissue that lies immediately beneath the neural tube. In vertebrates the notochord functions as a skeletal element during early embryogenesis and as a source of signals that pattern the neural tube and paraxial mesoderm. Despite the recent identification of mutations affecting notochord development in zebrafish, the rather modest progress in isolating genes expressed in the notochord during its differentiation has limited our understanding of the molecular mechanisms underpinning its structure and function. In a recent study, Takahashi et al. (1999), using embryos of the primitive chordate, the ascidian, have redressed the balance, identifying a large number of notochord-specific genes by subtractive cloning. Their approach, although not novel in principle, is remarkable for its efficacy and promises to set the stage for significant advances not only in our appreciation of the formation and function of the notochord but also in understanding how this important structure has evolved.

\section{Notochord specification and the role of Brachyury in mesodermal patterning}

In vertebrates, the notochord develops from the axial mesoderm of the gastrula via inductive interactions involving the transforming growth factor $\beta$ (TGF $\beta$ )-superfamily and fibroblast growth factor (FGF)-family signaling molecules. After neurulation the notochord lies beneath the floor plate of the neural tube, above the endoderm, and between the paired somites that extend the length of the trunk and the tail. Critical to its function, the notochord expresses transcription factors encoded by the Brachyury, HNF-3 $\beta$ and floating head genes (Smith et al. 1991; Ruiz i Altaba and Jessell 1992; Talbot et al. 1995), as well as the secreted factor Sonic hedgehog, which patterns the somites and the neural tube (for review, see Ingham 1995). Studies in the mouse, Xenopus, and zebrafish have demonstrated that Brachyury is required for differentiation of axial midline mesoderm into notochord as well as for the formation of posterior mesodermal tissues (Chesley 1935; Halpern et al. 1993; Schulte-Merker et al. 1992; Conlon et al. 1996).

Ascidian development is highly autonomous, yet in-

${ }^{1}$ Corresponding author.

E-MAIL p.w.ingham@sheffield.ac.uk; FAX 441142222788. ductive interactions are nevertheless critical for the establishment of some cell lineages (Nishida 1997). In these organisms, notochordal fate is induced by vegetal blastomeres in just 10 cells of the 110-cell embryo (Nakatani and Nishida 1994). These 10 cells then divide twice to produce the entire set of 40 cells that comprises the larval notochord. Initial expression of the Ciona intestinalis homolog of the vertebrate Brachyury gene, Ci$B r a$, coincides precisely with the restriction of early blastomeres to a notochordal fate (Yasuoh and Satoh 1993). Expression of Brachyury is then maintained exclusively in the notochord, in contrast to the situation in vertebrate embryos, where Brachyury is expressed in both notochord and ventral-posterior mesoderm (Fig. 1). Moreover, misexpression of ascidian Brachyury in cells of non-notochordal lineages is sufficient to impart to them with the morphological characteristics of notochord cells without the need for inductive interactions with vegetal blastomeres (Yasuo and Satoh 1998). Takahashi et al. (1999) have now extended this observation and demonstrated that misexpression of Brachyury in the endoderm of ascidian embryos is sufficient to induce fully differentiated ectopic notochord. This contrasts with the induction of ventral-posterior mesoderm observed when Brachyury was misexpressed in Xenopus animal caps (Cunliffe and Smith 1992): Only by coexpressing noggin with Brachyury could notochord be induced in this tissue (Cunliffe and Smith 1994). Significantly, Noggin is known to function by inhibiting bone morphogenetic protein (BMP) signaling pathways (Zimmerman et al. 1996); BMP4 can both ventralize dorsal mesoderm and induce epidermal fate in dissociated animal cap cells, and at high concentrations BMP4 is sufficient to induce ventral mesoderm in animal cap tissue (Dale et al. 1992; Jones et al. 1992. Sasai et al. 1995; Schmidt et al. 1995; Wilson and Hemmati-Brivanlou 1995). Thus, coexpression of Noggin with Brachyury in animal caps removes the ventralizing constraint of BMP signaling on mesodermal fate induced by Brachyury, yielding notochord and somitic muscle.

Although as in vertebrates, BMP signaling is implicated in epidermal induction and the inhibition of neural fate in ascidians, it appears to have no obvious role in the dorsoventral patterning of the mesoderm of these animals: Misexpression of BMP4 does not ventralize dorsal mesoderm, and in any case it is not expressed in the appropriate cell lineage (Miya et al. 1997). Similarly, studies of the expression pattern of $B M P 2 / 4$ in the 

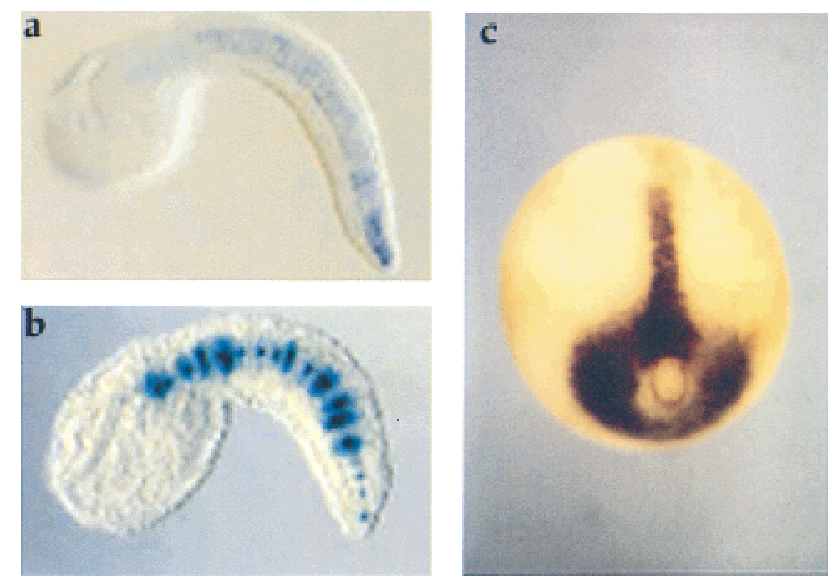

Figure 1. Expression of Brachyury in ascidian and Xenopus embryos. (a) In situ localization of Ci-Bra mRNA in mid-tailbud embryo of C. intestinalis. Signal is strongest in posterior notochord cells (1997). Anterior is to the left; dorsal is up. (b) Notochord-specific expression of the lacZ transgene under the control of the 3.5-kb Ci-Bra promoter in the mid-tailbud embryo of C. intestinalis $(a, b)$ Reprinted, with permission, from Corbo et al. 1997. Anterior is to the left; dorsal is up. (c) In situ localization of Xbra mRNA in late gastrula stage Xenopus embryo. Posterior view; dorsal is up. The signal is visible in two domains: notochord and ventral-posterior mesoderm.

cephalochordate Amphioxus indicate a function for this gene in specification of ectodermal fate but not in dorsoventral patterning of the mesoderm (Panopoulou et al. 1998). The absence of a ventralizing function of ascidian BMP4 may therefore explain how misexpression of Brachyury in ascidian endoderm leads directly to the formation of ectopic notochord.

Taken together, the observations of Ci-Bra and Xenopus Brachyury (Xbra) function have implications for the evolution of mesodermal patterning mechanisms. It is possible that the earliest evolutionary role for Brachyury in chordate development was to specify notochord, and that of BMP signaling may have been to induce epidermal fate. Subsequently, the function of BMP signaling in evolution may have been modified to influence the regulatory program under control of Brachyury. This would then have enabled the specification and patterning of several types of mesodermal tissues in the vertebrates in addition to notochord, including somite, mesenchyme, and mesothelium, in a BMP concentration-dependent manner.

The simple switch effect of Brachyury in ascidians has been exploited by Takahashi et al. (1999) to stunning effect. A high efficiency electroporation technique was used to introduce plasmid DNA encoding Ci-Bra under the control of the ascidian fork head/HNF-3 3 (Ci-fkh) promoter. Because the combined efficiencies of the electroporation technique and promoter construct used resulted in extremely high levels of Ci-Bra transcription and conversion of a large part of the embryo into notochord, these embryos represent an excellent source of material for subtractive hybridization approaches.

\section{Novel genes involved in notochord specification and function}

A subtractive library comprising 599 cDNA clones was produced, 501 of which were up-regulated in embryos expressing the $\mathrm{Ci}$-fkh/Ci-Bra construct. Of these, 38 exhibited a notochord-specific expression pattern by in situ hybridization, representing a frequency of $6 \%$ of the clones in the original library. Another $84(14 \%)$ induced cDNA clones exhibited expression in notochord and other discrete locations in the embryo, giving a total frequency of $20 \%$ notochord-induced cDNAs. However, a further $81(14 \%)$ of the induced clones exhibited specific expression patterns in locations other than the notochord, suggesting that signaling by ectopic notochord induces gene expression in other tissues.

Twenty of the 38 notochord-specific genes are suggested by Takahashi et al. (1999) to encode proteins with no sequence similarities in available databases. Given the number and size of the existing model genome and expressed sequence tag (EST) databases, this suggests that there are likely to be many specialized aspects of notochord function that remain to be understood. The remaining 18 genes encode products with sequence similarity to proteins of known function. These include extracellular matrix proteins, cell adhesion molecules, and cytoplasmic signaling pathway components. One gene that is expressed relatively late in notochord formation is a member of the ezrin-radixin-moesin (ERM) family of polypeptides, which tether components of the plasma membrane to the actin cytoskeleton (Tsukita and Yonemura 1997). Perhaps this ERM protein plays a role in cell intercalation, maintaining the integrity of the notochord or producing the changes in notochord cell shape that contribute to tail extension.

\section{Other Brachyury-inducible genes}

Tada et al. (1998) previously used a subtractive hybridization approach to isolate genes that were activated when Xbra was misexpressed in Xenopus animal cap tissue. Because no notochord is induced in this scenario, the functions of these putative Xbra target genes are unlikely to be related to those characterized by Takahashi et al. (1999). Of 37 cDNA clones from the subtracted library, 4 were identified as Brachyury inducible. One cDNA clone that was isolated identified a family of homeodomain protein-encoding cDNAs related to the Mix. 1 family of genes. This cDNA, Bix1, is expressed in mesoderm and endoderm at late blastula and gastrula stages but it is excluded from the dorsal marginal zone of the early gastrula that is fated to form the notochord. Misexpression of Bix1 in the dorsal marginal zone prevented notochord formation, whereas misexpression of Bix1 in animal cap tissue was sufficient to induce formation of ventral mesoderm. Thus Bix1 may be a direct target for Brachyury in the presence of BMP signaling and would not therefore be predicted to be activated by Ci-Bra in ascidians.

Another target gene of Xenopus Brachyury is eFGF 
(Casey et al. 1998), activity of which is required for Brachyury function in the specification of dorsal mesoderm including notochord (Isaacs et al. 1994; SchulteMerker and Smith 1995; Conlon et al. 1996). In this case, it seems surprising that no FGF homologs were identified in the collection of subtracted cDNA clones by Takahashi and colleagues (1999); this may indicate a further difference between the function of Brachyury in ascidians and vertebrates that merits further investigation.

\section{Endodermal competence and the role of T-box genes in endoderm formation}

The discovery that Ci-Bra can convert ascidian prospective endoderm into notochord demonstrates that in this species, prospective endoderm is competent to realize a mesodermal fate. However, as in vertebrates, the ascidian endoderm is the source of the notochord-inducing signal (Nakatani and Nishida 1994). A mechanism should therefore exist that blocks self-induction of $\mathrm{Ci}$ Bra in endoderm and thus prevents autodifferentiation into notochord.

No effects of misexpressing vertebrate Brachyury in Xenopus vegetal pole prospective endoderm have been reported, but the observation by Takahashi et al. (1999) of an experimentally produced endoderm-to-mesoderm fate switch is not without precedent in vertebrate embryos. Transcripts of the maternally expressed Xenopus T-box family member VegT are initially restricted in the early embryo to the vegetal hemisphere and later are distributed quite broadly throughout the mesoderm (Horb and Thomsen 1997; Lustig et al. 1996; Stennard et al. 1996; Zhang and King 1996). Misexpression of VegT in animal cap tissue causes mesoderm formation, but intriguingly, depletion of maternal VegT mRNA stores by oligonucleotide-mediated mRNA destruction results in the differentiation of prospective endoderm into mesoderm and of marginal zone prospective mesoderm into ectoderm (Zhang et al. 1998). Thus, whereas VegT fulfills one role in the mesoderm, it also is required in the prospective Xenopus endoderm for the specification of this germ layer.

Given that VegT and Xbra are highly related and can bind specifically to the same target sites (Tada et al. 1998), it is tempting to speculate that misexpression of Ci-Bra in ascidian endoderm diverts endoderm to a mesodermal fate both by competitive inhibition in the endoderm of a putative maternal VegT homologe, such as the gene described recently by Takada et al. (1998), as well as by promoting notochord differentiation.

This mutual competence of mesoderm and endoderm to form one or another tissue and the finding that they are controlled by related transcription factors are underscored further by the discovery that Bix1, which is inducible by both Xbra and VegT and is expressed in both mesoderm and endoderm, can specify differentiation of each tissue in animal cap explants (Tada et al. 1998). These observations raise the question of how these germ layers acquire such different fates while expressing very similar regulatory molecules.

\section{Implications for future studies-a general approach to analyzing chordate tissue specification}

In the zebrafish, screens for mutants have so far identified at least 29 genes that are required for notochord formation (Odenthal et al. 1996; Stemple et al. 1996). Genes such as bozozok and floating head control the formation of the axial midline mesodermal precursors, whereas no tail (zebrafish Brachyury) and gno are required for commitment to the notochord pathway of differentiation. Many of the other genes recovered in these screens appear to be involved in the differentiation, maintenance, and normal shape of the notochord and thus most likely act downstream of Brachyury. Because multiple alleles have been recovered at many of these loci, these aspects of notochord development may be close to saturation. Alternative approaches that augment the mutant analyses in the zebrafish will therefore be necessary if a complete description of notochord differentiation and function is to be realized. One route will undoubtedly be the characterization of vertebrate homologs of the genes isolated by Takahashi et al. (1999). It may turn out that some of these genes are homologs of those identified in the zebrafish screens for notochorddetermining genes. Further insights into the function of the genes that lack corresponding mutant zebrafish homologs should emerge from studying their expression patterns in the notochord mutants produced in the Tübingen and Cambridge screens.

A frequency of $20 \%$ notochord-induced cDNA clones in the Ci-Bra-specific subtractive library indicates that the procedure of Takahashi and coworkers (1999) is reasonably efficient and may be more widely applicable to the identification of target genes that are under the control of other transcription factors and inducing factors.

Comparative evolutionary studies of developmental regulatory genes are becoming increasingly important for understanding how the mechanisms of developmental patterning operate. Moreover, studies of ascidian embryos are gaining popularity because their uncomplicated body plan is fundamentally similar to those of vertebrate embryos and because of their highly conserved homologs of key vertebrate patterning genes. Such features, along with the small genome size and the recently improved methods with which to study gene function in ascidians, suggest that rapid progress will be made with these organisms in understanding the conserved molecular mechanisms that specify the axes and components of the chordate body plan.

\section{Acknowledgments}

We are grateful to The Company of Biologists Limited for permission to use Figure $1 \mathrm{a}$ and $1 \mathrm{~b}$, and to Dr. J.C. Smith for permission to use Figure 1c. V.T.C. is a Lister Institute Research Fellow.

\section{References}

Casey, E.S., M-A.J. O’Reilly, F.L. Conlon, and J.C. Smith. 1998. The T-box transcription factor Brachyury regulates expres- 
sion of $e F G F$ through binding to a non-palindromic response element. Development 125: 3887-3894.

Chesley, P. 1935. Development of the short-tailed mutant in the house mouse. J. Exp. Zool. 70: 429-459.

Conlon, F.L., S.G. Sedgwick, K.M. Weston, and J.C. Smith. 1996. Inhibition of Xbra transcription activation causes defects in mesodermal patterning and reveals autoregulation of Xbra in dorsal mesoderm. Development 122: 2427-2435.

Corbo, J.C, M. Levine, and R.W. Zeller. 1997. Characterization of a notochord- specific enhancer from the Brachyury promoter region of the ascidian, Ciona intestinalis. Development 124: 589-602.

Cunliffe, V. and J.C. Smith. 1992. Ectopic mesoderm formation in Xenopus embryos caused by widespread expression of a Brachyury homologue. Nature 358: 427-430.

- 1994. Specification of mesodermal pattern in Xenopus laevis by interactions between Brachyury, noggin, and Xwnt-8. EMBO J. 13: 349-359.

Dale, L., G. Howes, B.M.J. Price, and J.C. Smith. 1992. Bone morphogenetic protein 4: A ventralizing factor in early Xenopus development. Development 115: 573-585.

Halpern, M.E., R.K. Ho, C. Walker, and C.B. Kimmel. 1993. Induction of muscle pioneers and floor plate is distinguished by the zebrafish no tail mutation. Cell 75: 99-111.

Horb, M.E. and G.H. Thomsen. 1997. A vegetally localized Tbox transcription factor in Xenopus eggs specifies mesoderm and endoderm and is essential for embryonic mesoderm formation. Development 124: 1689-1698.

Ingham, P.W. 1995. Signalling by hedgehog family proteins, in Drosophila and vertebrate development. Curr. Opin. Genet. Dev. 5: 492-498.

Isaacs, H.V., M.E. Pownall, and J.M.W. Slack. 1994. eFGF regulates Xbra expression during Xenopus gastrulation. EMBO $J$. 13: 4469- 4481.

Jones, C.M., K.M. Lyons, Lapan, P.M., C.V.E. Wright, and B.L.M. Hogan. 1992. DVR-4 (bone morphogenetic protein-4) as a posterior ventralizing factor in Xenopus mesoderm induction. Development 115: 639-647.

Lustig, K.D., K.L. Kroll, E.E. Sun, and M.W. Kirschner. 1996. Expression cloning of a Xenopus T-related gene (Xombi) involved in mesodermal patterning and blastopore lip formation. Development 122: 4001- 4012.

Miya, T., K. Morita, A. Suzuki, N. Ueno and N. Satoh. 1997. Functional analysis of an ascidian homologue of vertebrate $B m p-2 / B m p-4$ suggests its role in the inhibition of neural fate specification. Development 124: 5149- -5159.

Nakatani, Y. and H. Nishida. 1994. Induction of notochord during ascidian embryogenesis. Dev. Biol. 166: 289-299.

Nishida, H. 1997. Cell fate specification by localized cytoplasmic determinants and cell interactions in ascidian embryos. Int. Rev. Cytol. 176: 245-306.

Odenthal, J., P. Haffter, E. Vogelsang, M. Brand, F.J.M. van Eeden, M. Furutani-Seiki, M. Granato, M. Hammerschmidt, C-P. Heisenberg, Y-J. Jiang, D.A. Kane, R.N. Kelsh, M.C. Mullins, R.M. Warga, M.L. Allende, E.S. Weinberg and C. Nüsslein-Volhard. 1996. Mutations affecting the formation of the notochord in the zebrafish, Danio rerio. Development 123: $103-115$.

Panopoulou G.D., M.D. Clark, L.Z. Holland, H. Lehrach, and N.D. Holland. 1998. AmphiBMP2/4, an Amphioxus bone morphogenetic protein closely related to Drosophila decapentaplegic and vertebrate $B M P 2$ and $B M P 4$ : insights into evolution of dorsoventral axis specification. Dev. Dyn. 13: 130-139.

Ruiz i Altaba, A. and T.M. Jessell. 1992 Pintallavis, a gene expressed in the organizer and midline cells of frog embryos:
Involvement in the development of the neural axis. Development 116: 81-93.

Sasai, Y., B. Lu, H. Steinbeisser, and E.M. DeRobertis. 1995. Regulation of neural induction by the Chd and Bmp-4 antagonistic patterning signals in Xenopus. Nature 376: 333-336.

Schmidt, J.E., A. Suzuki, N. Ueno, and D. Kimelman. 1995. Localized BMP-4 mediates dorsal/ventral patterning in the early Xenopus embryo. Dev. Biol. 169: 37-50.

Schulte-Merker, S., R.K. Ho, B.G. Herrman, and C. NüssleinVolhard. 1997. The protein product of the zebrafish homologue of the mouse T gene is expressed in nuclei of the germ ring and the notochord of the early embryo. Development 116: 1021-1032.

Schulte-Merker, S. and J.C. Smith. 1995. Mesoderm formation in response to Brachyury requires FGF signalling. Curr. Biol. 5: 62-67.

Smith, J.C., B.M.J. Price, J.B.A. Green, D. Weigel, and B.G. Herrmann. 1991. Expression of a Xenopus homolog of Brachyury $(T)$ is an immediate- early response to mesoderm induction. Cell 67: 79-87.

Stemple, D.L., L. Solnica-Krezel, F. Zwartkruis, S.C.F. Neuhauss, A.F. Schier, J. Malicki, D.Y.R. Stainier, S. Abdelilah, Z. Rangini, E. Mountcastle-Shah, and W. Driever. 1996. Mutations affecting development of the notochord in zebrafish. Development 123: 117-128.

Stennard, F., G. Carnac, and J.B. Gurdon. 1996. The Xenopus T-box gene, Antipodean, encodes a vegetally-localised maternal mRNA and can trigger mesoderm formation. Development 122: 4179-4188.

Tada, M., E.S. Casey, L. Fairclough, and J.C. Smith. 1998. Bix1, a direct target of Xenopus T-box genes, causes formation of ventral mesoderm and endoderm. Development 125: 39974006.

Takada, N., K. Tagawa, H. Takahashi, and N. Satoh. 1998. Characterization of an ascidian maternal T-box gene, As-mT. Int. J. Dev. Biol. 42: 1093-1100.

Takahashi, H., K. Hotta, A. Erives, A. Di Gregorio, R.W. Zeller, M. Levine, and N. Satoh. 1999. Brachyury-downstream notochord differentiation in the ascidian embryo. Genes \& Dev. 13: 1519-1523.

Talbot, W.S., B. Trevarrow, M.E. Halpern, A.E. Melby, G. Farr, J.H. Postlethwait, T. Jowett, C.B. Kimmel, and D. Kimelman. 1995. A homeobox gene essential for zebrafish notochord development. Nature 378: 150-157.

Tsukita, S. and S. Yonemura. 1997. ERM (ezrin/radixin/moesin) family: From cytoskeleton to signal transduction. Curr. Opin. Cell Biol. 9: 70- 75.

Wilson, P. and A. Hemmati-Brivanlou. 1995. Induction of epidermis and inhibition of neural fate by Bmp-4. Nature 376: 331-333.

Yasuo, H. and N. Satoh. 1993. Function of vertebrate T gene. Nature 364: 582-583.

- 1998. Conservation of the developmental role of Brachyury in notochord formation in a urochordate, the ascidian Halocynthia roretzi. Dev. Biol. 200: 158-170.

Zhang, J. and M.L. King. 1996. Xenopus VegT RNA is localized to the vegetal cortex during oogenesis and encodes a novel T-box transcription factor involved in mesodermal patterning. Development 122: 4119-4129.

Zhang, J., D.W. Houston, M.L. King, C. Payne, C. Wylie, and J. Heasman. 1998. The role of maternal VegT in establishing the primary germ layers in Xenopus embryos. Cell 94: 515524.

Zimmerman, L.B., J.M. De Jesus-Escobar, and R.M. Harland. 1996. The Spemann organizer signal noggin binds and inactivates bone morphogenetic protein 4. Cell 86: 599-606. 


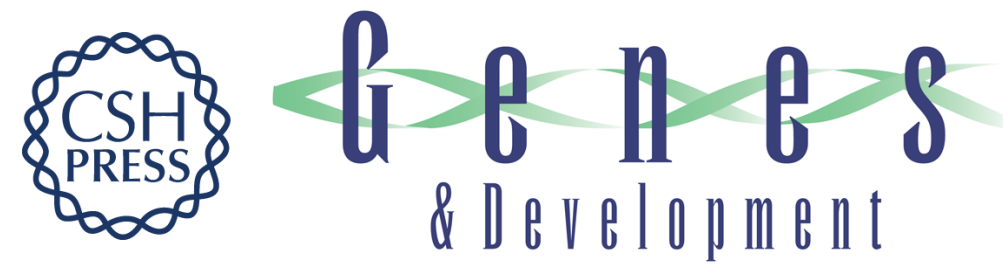

\section{Switching on the notochord}

Vincent T. Cunliffe and Philip W. Ingham

Genes Dev. 1999, 13:

References This article cites 36 articles, 16 of which can be accessed free at: http://genesdev.cshlp.org/content/13/13/1643.full.html\#ref-list-1

License

Email Alerting

Receive free email alerts when new articles cite this article - sign up in the box at the top Service right corner of the article or click here.

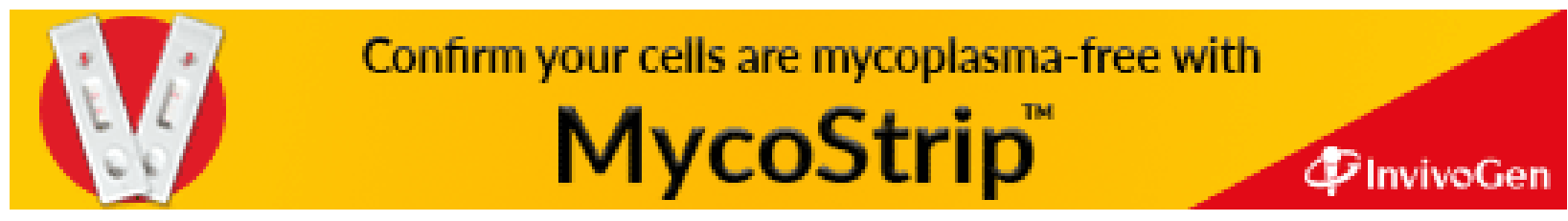

